\title{
Use of Transmission Electron Microscopy in Combinatorial Studies of Functional Oxides
}

\author{
Leonid A. Bendersky ${ }^{(a)}$ and Ichiro Takeuchi ${ }^{(b)}$ \\ (a) Metallurgy Division, NIST, Gaithersburg, MD 20886 USA \\ (b) Department of Materials Science and Engineering and Center for Superconductivity Research, \\ University of Maryland, College Park, MD 20742 USA
}

The combinatorial approach to materials is an emerging paradigm of research methodology that aims to drastically increase the efficiency at which new compounds and improved properties are discovered. In a single experiment, hundreds of different compositions can be synthesized and screened for desired physical properties. The principles of combinatorial techniques are based on high-throughput properties measurements (HTPM) of multiple compositions in combinatorial libraries, and recently being increasingly applied in materials research [1].

With recent development of new tools for HTPM, it became possible to measure different physical properties of combinatorial libraries using small probes, and relate the properties to the local composition and structure. Many of the properties are critically dependent on crystallographic and microstructural details of the material. For now, the characterization tool used for combinatorial studies are too basic to reveal such details as precise symmetry of phases, distribution of domains, presence and type of defects, compositional fluctuations etc. Knowledge of such details are essential for understanding the measurements, but also important in establishing reliable and reproducible fabrication processes of combinatorial libraries.

It appears that, in spite of the combinatorial philosophy of fast and massive experimentation, the use of transmission electron microscopy (TEM) should be an important part of some combinatorial investigations. In the paper we present two examples from our combinatorial studies of functional oxides where the TEM investigation was essential in obtaining detailed picture of microstructures and its relationship to the measured properties. In both cases the combinatorial libraries were prepared in a form of thin film compositional spreads using shutter-controlled pulsed laser deposition [2]. The compositional gradients were obtained by depositing alternating, wedge-like layers of the end-member compositions. In order to ensure alloy-like intermixing of the endmembers, thickness of the wedges was less than $0.4 \mathrm{~nm}$.

$\mathrm{ZnO}-\mathrm{MgO}$ system. $\mathrm{ZnO}$ (wurtzite structure) is a wideband gap semiconductor similar to GaN. The effect of $\mathrm{MgO}$ on the band gap and optical properties of $\mathrm{ZnO}$ was studied by preparing a compositional spread $\mathrm{ZnO}-\mathrm{MgO}$ on a sapphire substrate. Optical measurements showed that in the low $\mathrm{Mg}(\mathrm{Mg}<30 \%)$, the gap changes linearly from $3.27 \mathrm{eV}$ to $4.28 \mathrm{eV}$, and for $\mathrm{Mg}>30 \%$ there is no well-defined bandgap [3]. TEM investigation showed that for $\mathrm{MgO}<30 \%$ the structure is a solid solution of epitaxial wurtzite, with high density of planar defects. For $30<\mathrm{MgO}<60 \%$, the microstructure consists of two phases, $\mathrm{ZnO}$ and $\mathrm{MgO}$, and the phases are in an unusual orientation relationship with a 6-fold axis of $\mathrm{ZnO}$ parallel to a 4-fold axis of $\mathrm{MgO}$ (Fig. 1a). For higher $\mathrm{MgO}$ compositions, the film has $<111>$-oriented columnar grains of $\mathrm{MgO}$, and the grains are in a twin orientation relationship (Fig. 1b).

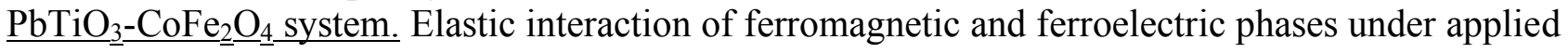
fields in a two-phase multiferroic material can exhibit magnetoelectric effects, which are of great interest for novel device applications. $\mathrm{CoFe}_{2} \mathrm{O}_{4}$ (ferroelectric perovskite) and $\mathrm{CoFe}_{2} \mathrm{O}_{4}$ (ferromagnetic spinel) phases were selected to form a multiferroic thin film and studied for the magnetoelectric effect. $\mathrm{PbTiO}_{3}-\mathrm{CoFe}_{2} \mathrm{O}_{4}$ compositional spreads were synthesized using multilayers 
of different thicknesses, and the magnetoelectic effect was found for a composition $0.8 \mathrm{PbTiO}_{3}$ $0,2 \mathrm{CoFe}_{2} \mathrm{O}_{4}$. Microstuctures in a wide range of compositions consist of a matrix of $\mathrm{CoFe}_{2} \mathrm{O}_{4}$ and pancake-like grains of $\mathrm{PbTiO}_{3}$ in the cube-to-cube orientation relationship, Fig. 2a. Solubility of $\mathrm{CoFe}_{2} \mathrm{O}_{4}$ in $\mathrm{PbTiO}_{3}$ was found, Fig. 2b, and the presence of $\mathrm{CoFe}_{2} \mathrm{O}_{4}$ causes dramatic reduction in ferroelectric and structural (cubic to tetragonal) transition temperature of $\mathrm{PbTiO}_{3}$.

\section{References:}

1. Proceedings of the US-Japan Workshop, Appl. Surf. Sci., 2002, 189 (3-4)

2. I. Takeuchi, K. Chang, R. P. Sharma, L. A. Bendersky, H. Chang, X.-D. Xiang, E. A. Stach, C.-Y. Song, J. Appl. Phys., 2001, 90, 2474

3. I. Takeuchi et al., J. Appl. Phys., 94, 7336 (2003)
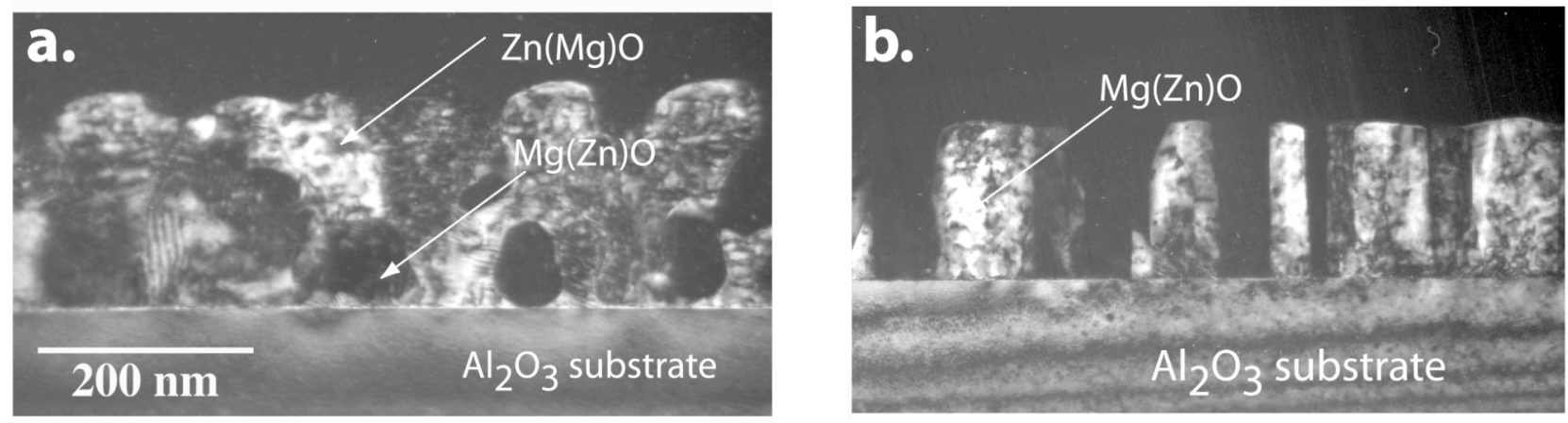

FIG. 1. (a) Cross-sectional TEM (dark field) micrograph of a $\mathrm{MgO}=50 \%$ section showing the twophase structure. (b) Cross-sectional dark field image of a $\mathrm{MgO}=90 \%$ section showing columnar grains of the $\mathrm{MgO}$ phase.
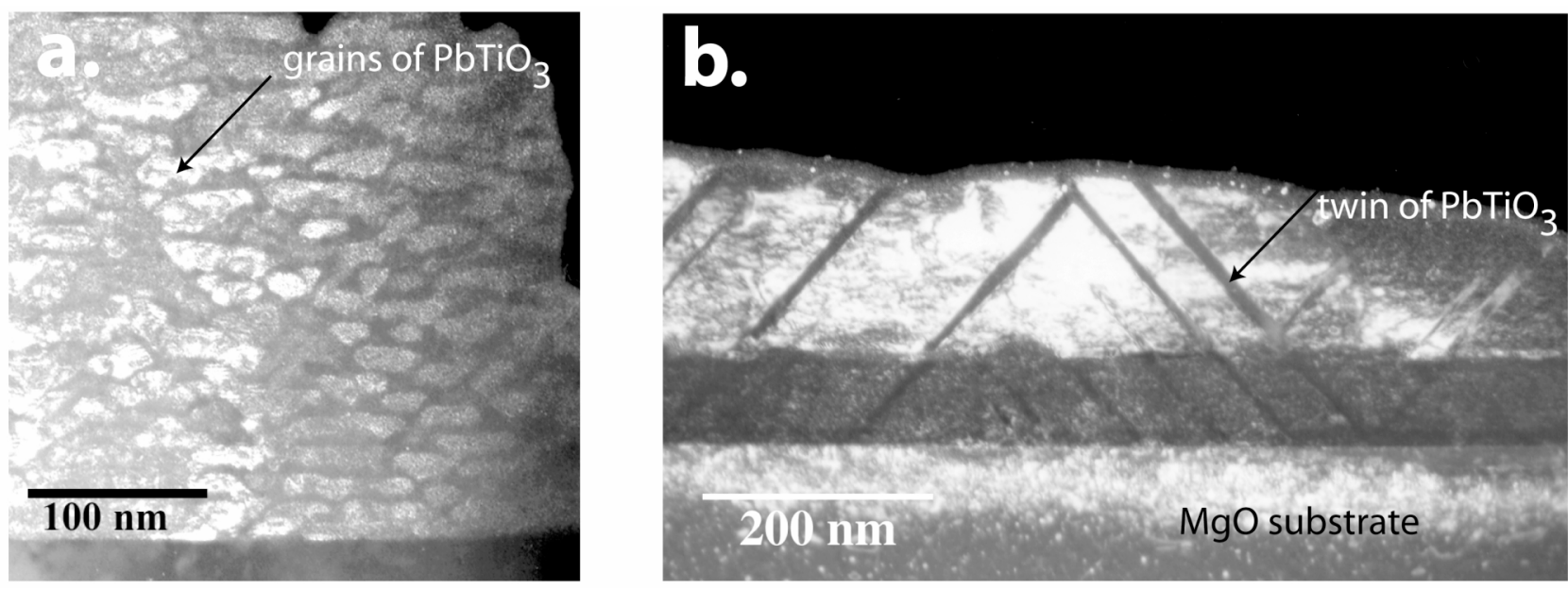

FIG. 2. (a) Cross-sectional TEM (dark field) micrograph of a $0.8 \mathrm{PbTiO}_{3}-0.2 \mathrm{CoFe}_{2} \mathrm{O}_{4}$ section showing pancake-like grains of a cubic $\mathrm{PbTiO}_{3}$ in a matrix of $\mathrm{CoFe}_{2} \mathrm{O}_{4}$. (b) Cross-sectional TEM (dark field) micrograph of a $0.95 \mathrm{PbTiO}_{3}-0.05 \mathrm{CoFe}_{2} \mathrm{O}_{4}$ section showing a single phase $\mathrm{PbTiO}_{3}$. The presence of twins demonstrates that the phase is tetragonal. 